\title{
O papel do coordenador pedagógico e a repercussão no processo de gestão escolar
}

\author{
The role of the pedagogical coordinator and the impact on the school management process \\ El papel del coordinador pedagógico y la repercusión en el proceso de gestión escolar
}

Recebido: 24/11/2021 | Revisado: 30/11/2021 | Aceito: 03/12/2021 | Publicado: 12/12/2021

\author{
Alan Maciel Guterres \\ ORCID: https://orcid.org/0000-0002-4901-8370 \\ Universidade Franciscana, Brasil \\ E-mail:alan.guterres@ufn.edu.br \\ Eliane Aparecida Galvão dos Santos \\ ORCID: https://orcid.org/0000-0002-3982-7297 \\ Universidade Franciscana, Brasil \\ E-mail: elianea@ufn.edu.br
}

\begin{abstract}
Resumo
O artigo discute sobre a atuação do coordenador pedagógico na gestão da escola, trazendo a problemática: qual o papel do coordenador pedagógico e a repercussão no processo de gestão escolar? A pesquisa é de abordagem qualitativa, do tipo bibliográfica e tem como fundamentação teórica os documentos, decretos, resoluções e autores que discorrem a respeito do tema abordado. O objetivo do estudo é compreender o papel do coordenador pedagógico e a repercussão de suas ações no processo de gestão escolar. Os resultados da pesquisa mostram que o papel do coordenador pedagógico começou a delinear-se a partir da década de 1980, com a Promulgação da Constituição Federal, que enfatiza a gestão democrática, a descentralização do poder e a tomada de decisão, no que tange aos aspectos educativos. Somente em 1996, com a promulgação da Lei de Diretrizes e Bases da Educação, nº $9394 / 96$ é que surge a figura do coordenador pedagógico, como especialista em educação, como articulador e mobilizador de todos os processos pedagógicos que acontecem no cotidiano escolar. Essa reflexão e discussão sobre o papel desse profissional vem sendo preconizada nos dias atuais, sobretudo, embasada em resoluções e decretos promulgados pelos órgãos federais.
\end{abstract}

Palavras-chave: Gestão democrática; Coordenação pedagógica; Educação.

\begin{abstract}
The article discusses the role of the pedagogical coordinator in school management, bringing the issue: what is the role of the pedagogical coordinator and the impact on the school management process? The research has a qualitative approach, of the bibliographic type, and has as theoretical foundation the documents, decrees, resolutions and authors that discuss the topic discussed. The aim of the study is to understand the role of the pedagogical coordinator and the impact of their actions on the school management process. The research results show that the role of the pedagogical coordinator began to take shape in the 1980s, with the Promulgation of the Federal Constitution, which emphasizes democratic management, decentralization of power and decision-making, about educational aspects. It was only in 1996, with the enactment of the Law of Guidelines and Bases of Education, $\mathrm{n}^{\circ}$ 9394/96, that the figure of the pedagogical coordinator emerged, as a specialist in education, as an articulator and mobilizer of all pedagogical processes that take place in everyday school life. This reflection and discussion on the role of this professional has been advocated nowadays, above all, based on resolutions and decrees promulgated by federal agencies.
\end{abstract}

Keywords: Democratic management; Pedagogical coordination; Education.

\section{Resumen}

El artículo discute sobre la actuación del coordinador pedagógico en la gestión de la escuela, abordando la problemática: ¿Cuál es el papel del coordinador pedagógico y la repercusión en el proceso de la gestión escolar? La pesquisa es cualitativa, bibliográfica y como fundamentación teórica los documentos, decretos, resoluciones y autores que discuten sobre el tema abordado. El objetivo del estudio es comprender el papel del coordinador pedagógico y la repercusión de sus acciones en el proceso de gestión escolar. Los resultados de la pesquisa evidencian que el papel del coordinador pedagógico empezó a delinearse a partir de la década de 1980, con la promulgación de la Constitución Federal, que enfatiza la gestión democrática, la descentralización del poder y la tomada de decisión, refiriéndose a los aspectos educativos. Solamente en 1996, con la promulgación de la Ley de Directrices y Bases de la Educación, $\mathrm{n}^{\circ}$ 9394/96, es que surge la imagen del coordinador pedagógico, como especialista en educación, como articulador y movilizador de todos los procesos educativos que ocurren en la escuela. Esa reflexión y discusión sobre el papel dese profesional se ha defendido hoy en día, en los decretos y resoluciones promulgados por las organizaciones federales.

Palabras clave: Gestión democrática; Coordinación pedagógica; Educación. 


\section{Introdução}

Quando se discute educação, sobretudo a escolar, não se pode deixar de mencionar a importância do trabalho de gestão da escola, pois esses processos envolvem, necessariamente, a tomada de decisões a respeito das ações que serão implementadas no âmbito dos espaços educativos formais. Nesse sentido, pontua-se o conceito de gestão, o qual traz diversos significados e atribuições, dependendo da concepção que se tem do que significa gestar. Pode ser entendido como o ato de gerir, de administrar, de organizar um determinado espaço em vista das necessidades dos sujeitos que dele fazem parte. Já, Lück (2009) afirma que "é um processo pelo qual se mobiliza e coordena o talento humano, coletivamente organizado, de modo que as pessoas, em equipe, possam promover resultados desejados” Partindo das ideias de Lück amplia-se a discussão a respeito da gestão escolar e suas implicações no que tange ao cenário educativo escolar.

Nesse sentido, a Gestão Escolar é um processo em que, a partir dos objetivos da instituição escolar, os gestores mobilizam, articulam os meios para que os integrantes da comunidade escolar assumam seus papéis e desenvolvam ações com vistas a atingir os objetivos almejados. Nessa direção, implica em todo o processo educativo desenvolvido na escola, o qual é liderado por uma equipe de docentes/gestores pertencentes à escola. Este processo de gestão deve ser participativo, isto é, não centrado na figura do diretor ou do vice diretor, mas de todos os sujeitos que compõem a equipe gestora da escola, primando pela participação das outras instâncias colegiadas, como os Conselhos Escolares, o Círculo de Pais e Mestres e o Grêmio Estudantil que, junto com a equipe gestora, articulam e ajudam a construir uma escola de qualidade, conforme garante o princípio colocado no Artigo 206, $§ 6$ da Constituição Federal, Brasil (1988) em que enfatiza a gestão democrática do ensino público, através da participação de todos os envolvidos nesse processo.

A gestão democrática caracteriza-se pela participação de toda a comunidade escolar onde cada instância colegiada se envolve na construção e realização de projetos que contribuam para a melhoria da qualidade de todos os âmbitos da escola. A intenção, na gestão democrática, é garantir a transparência nas ações, a partir da união de ideias e esforços que venham a favorecer a conquista de maior autonomia à escola. Portanto, a ênfase do gestão democrática está na valorização da, segundo Libâneo (2018) "participação da comunidade escolar no processo de tomada de decisão, na construção coletiva dos objetivos e das práticas escolares, no diálogo e na busca de consenso".

Nesse processo, surge uma discussão acerca dos profissionais da Educação que atuam mais especificamente na gestão da escola, e um deles é o coordenador pedagógico, centro da discussão desse estudo. O coordenador pedagógico tem papel fundamental para que a escola se torne democrática, pois ele trabalha diretamente com o âmbito do ensino e da aprendizagem, sendo um mediador juntamente com os demais integrantes da equipe gestora, o qual busca articular professores, alunos e famílias para a criação de projetos inovadores que tenham impacto no ensino e na aprendizagem.

Esse profissional tem como formação o curso de licenciatura e, de acordo com cada sistema de ensino, são exigidas formações complementares em nível lato sensu ou stricto sensu. Assim sendo, na maioria das vezes é um professor, um licenciado em alguma área específica do magistério, que passa por processos constitutivos da construção da sua identidade formativa em todas as suas instâncias, que atuou e, em alguns casos, atua ainda em sala de aula como professor regente sendo convidado para assumir um cargo, passando a integrar uma equipe gestora, exercendo o papel de articulador do processo educativo, juntamente com seus demais colegas, com um olhar mais voltado ao pedagógico, às questões relacionadas à aprendizagem.

Como o Coordenador Pedagógico tem a sua formação inicial na docência, ou seja, é um professor, e por já ter vivenciado a docência, ele poderá ter maior habilidade e empatia para trabalhar de forma mais direta com os professores, percebendo suas dificuldades, procurando ajudá-los, sendo suporte em todos os momentos do fazer pedagógico. Ele é o elo entre os demais membros da equipe gestora e com os demais segmentos da escola, na construção do Projeto Político Pedagógico, no acompanhamento do processo de aprendizagem, como também é o responsável por oportunizar a formação 
continuada dos professores. Desse modo, Ferreira (2012) enfatiza que o coordenador pedagógico é o "importante elemento integrante da gestão da educação, responsável pela garantia da qualidade do processo educacional que ocorre na escola e no sistema, coloca-se imperiosamente a formação como centro do trabalho".

A partir dessa contextualização, inicial, o problema de pesquisa que se busca responder neste estudo é: Qual o papel do coordenador pedagógico e a repercussão no processo de Gestão escolar?

Caracteriza-se como um recorte da pesquisa de mestrado que está sendo realizada pelo primeiro autor, no curso de Mestrado em Ensino de Humanidades e Linguagens da Universidade Franciscana/Santa Maria/RS.

\section{Metodologia}

Essa pesquisa é de abordagem qualitativa. Segundo Richardson (2012), a pesquisa é caracterizada como a tentativa de uma compreensão detalhada dos significados e características situacionais apresentadas (...), em lugar da produção de medidas quantitativas de características ou de comportamento. O tipo de pesquisa caracteriza-se por um estudo de natureza bibliográfica a qual "oferece o suporte a todas as fases de qualquer tipo de pesquisa, uma vez que auxilia na definição do problema, na determinação dos objetivos, na construção de hipóteses, na fundamentação da justificativa da escolha do tema e na elaboração do relatório final Fontana (2018). Assim sendo, esse estudo de revisão da literatura faz parte da pesquisa maior do primeiro autor que trata de investigar o papel do coordenador pedagógico e sua repercussão no processo de Gestão escolar em escolas da Rede Pública Municipal de uma cidade localizada no interior do Rio Grande do Sul.

\section{Discussão}

\subsection{O coordenador Pedagógico: uma discussão histórica}

O termo coordenador pedagógico é relativamente recente, se institui a partir dos anos 1980, em substituição à supervisão pedagógica, em que a formação inicial do supervisor se materializava no curso de pedagogia, baseada na Lei de Diretrizes e Bases no. 5.692/71. O termo "Supervisão Escolar" vem da Grécia Antiga, quando os gregos utilizavam esse termo para designar alguém que tinha uma "super visão", ou seja, que olhava de cima, que tinha uma visão ampla e superior sobre as coisas, como alguém que tinha o controle, como fiscalizador.

Essa visão e conceito designado ao Supervisor perdurou no Brasil, especificamente até o final da década de 60 e durante a década de 70, pois antes desse período não havia nenhuma valorização e formação específica para o Supervisor Escolar, ou seja, não havia um balizamento na Lei que regia a Educação da época.

No Brasil, a Supervisão Educacional começou a ganhar espaço na década de 70, a partir do Golpe Militar de 1964, onde o cenário educacional que predominava no Brasil estava em transição da Escola Nova para o tecnicismo. Esse momento histórico pela qual nosso país viveu, foi marcado por uma educação ainda autoritária, mas com um viés mais técnico, com o objetivo de formar profissionais, principalmente para o Ensino técnico e para o trabalho, conforme afirma Ferreira (2009): que “ainda neste período não há uma formação específica que habilite o Supervisor Escolar, ou seja, não há um corpo teórico/metodológico que o sustente como tal, reduzindo o trabalho deste profissional apenas como uma técnica e como uma burocratização".

A partir deste cenário educacional delineado anteriormente e com a publicação de mais uma Legislação que balizará a Educação no Brasil, ainda em período de Ditadura Militar, a Lei no 5692 de 11 de agosto de 1971, onde ratifica o que havia sido publicado na Lei anterior (Lei 5540/68), a respeito da formação dos Especialistas em Educação, onde na então Lei 5692/71, Brasil (1971), no artigo 33 vai reforçar a formação que se dará através de curso superior, para os cargos de supervisor, orientador e demais especialidades, que poderá ser com licenciatura curta ou plena, ou a nível de pós-graduação.. 
Com a promulgação da Constituição Federal de 1988, instaura-se a democracia no Brasil, e, com isso, surge a ideia de gestão democrática, tendo em vista a descentralização do poder, promovendo ações conjuntas entre a escola e a comunidade, com a finalidade de garantir a aprendizagem dos alunos.

Nesse novo cenário, é que surge a figura do coordenador pedagógico, como articulador e mobilizador do processo de gestão democrática na escola, visto que ele trabalha em conjunto com os demais membros da equipe gestora, que juntos articulam e mobilizam todas as ações educativas com vistas a garantir uma educação de qualidade, como também a aprendizagem dos alunos.

Em 1996, com a promulgação da Lei 9.394/96 (Lei de Diretrizes e Bases da Educação Nacional), como também as resoluções e decretos que foram promulgados subsequentes, e que estão em vigor até os dias atuais, garante, além da aprendizagem dos alunos, a formação dos profissionais da educação, dentre elas, destaca-se as diretrizes para os planos de carreira do magistério a nível federal, estadual e municipal, onde, a partir dessa nova legislação o coordenador pedagógico já é mencionado como profissional que tem garantida a sua profissão no plano de carreira.

\subsection{A gestão escolar democrática e o coordenador pedagógico}

O processo de mudança na educação, especialmente no Brasil, iniciou-se na década de 1980, quando começaram a surgir os movimentos sociais. Nesse período, com a promulgação da Constituição Federativa do Brasil, aprovada em 1988, começou-se a buscar uma abertura, por parte das escolas, no que diz respeito ao processo de gestão, de forma mais participativa e que garantisse o acesso e à permanência a todos.

É importante salientar o que diz a legislação tanto Constituição Federal, no Art. 206, no inciso VI, como também na LDB 9394/96, nos Artigos 14 e 15, (Brasil, 2010) que assim ressaltam:

Os sistemas de ensino definirão as normas da gestão democrática do ensino público na educação básica, de acordo com as suas peculiaridades e conforme os seguintes princípios: I. Participação dos profissionais da educação na elaboração do projeto pedagógico da escola; II. Participação das comunidades escolar e local em conselhos escolares ou equivalentes.

Art. 15 - Os sistemas de ensino assegurarão às unidades escolares públicas de educação básica que os integram progressivos graus de autonomia pedagógica e administrativa e de gestão financeira, observadas as normas de direito financeiro público e deve fazer parte do ensino público, ela está sendo desenvolvida de várias maneiras e com diferentes definições, como, gestão participativa cogestão entre outros e com isso são colocadas em prática com concepções diferenciadas e cabe a cada sistema de ensino decidir as normas que irão ser seguidas na gestão democrática. (Brasil, 2010, p.41)

A partir do exposto, evidencia-se que a gestão democrática nas escolas deve ser compartilhada, pensada e gestada no coletivo, onde todos participem de forma a contribuir para que o processo educativo aconteça de forma efetiva. A partir dessa nova realidade, a gestão escolar caracterizou-se de uma nova forma, através da descentralização do poder e da busca pela autonomia, buscando um diálogo mais aberto com as demais instâncias que compõem o cenário educativo e fora dele, conforme afirma Lück (2017):

O entendimento do conceito de gestão, portanto, por assentar-se sobre a maximização dos processos sociais como força e ímpeto para a promoção de mudanças, já pressupõe, em si, a ideia de participação, isto é, do trabalho associado e cooperativo de pessoas na análise de situações na tomada de decisão sobre seu encaminhamento e na ação sobre elas, em conjunto, a partir de objetivos organizacionais entendidos e abraçados por todos. (Lück, 2017, p.21).

Desse modo, faz-se necessário trazer à baila a discussão sobre o conceito de gestão escolar. O termo gestão escolar, que parte de um processo de superação da abordagem limitadora do termo administração, pois esse termo carrega um conceito técnico, sendo que os problemas educacionais são muito mais complexos e carecem de um olhar mais abrangente. A gestão 
escolar parte do pressuposto de gerir e conduzir o processo educativo na escola, em todas as suas instâncias, seja ela administrativa, pedagógica, financeira de forma integrada. Nesse sentido, Rodrigues e Santos (2019), destacam que:

Assim, a gestão escolar é vista como um processo que envolve a organização, participação da comunidade escolar e o funcionamento da escola nos aspectos políticos, administrativos e educacionais. Nesse sentido, a gestão da escola exige um posicionar-se diante das alternativas e todas as ações desenvolvidas na escola, envolvem atores e tomadas de decisões, pois são ações que expressam interesses, princípios e compromissos que auxiliam nas escolhas e nos rumos tomados pela escola. (Rodrigues \& Santos, 2019. p. 8).

Com isso, é tarefa da escola, sobretudo dos envolvidos no processo de gestão, garantir que a tomada de decisões e a participação de todos os sujeitos seja garantido.

Fazendo uma relação com todos os aspectos já abordados, menciona-se os princípios da gestão escolar democrática, onde a aplicação desses na escola vai depender em grande medida, em como os integrantes da equipe gestora irão colocar em prática esses princípios. A realização da gestão democrática é um princípio expresso na Lei de Diretrizes e Bases da Educação Nacional (Art. $3^{\circ}$. Inciso VIII), e na Constituição Federal (Art. 206, inciso VI).

Os princípios da gestão democrática são os seguintes: autonomia, a relação entre a direção e a participação da comunidade escolar, o envolvimento da comunidade no processo escola, o planejamento, a formação continuada dos integrantes da comunidade escolar, a análise dos problemas e a divulgação de suas informações, a avaliação compartilhada e as relações humanas estabelecidas na escola. O coordenador pedagógico desempenha um papel fundamental, no sentido de mobilizar e acompanhar o cumprimento e a efetivação desses princípios na comunidade escolar.

\subsection{As atribuições do coordenador pedagógico e sua atuação}

Nesse tópico discute-se sobre as atribuições do coordenador pedagógico e sua atuação, partindo, mais especificamente da LDB 9394/96, a partir do artigo 64, que vai discorrer a respeito da formação desses profissionais.

O Artigo 64 da LDB, mais especificamente, vai mostrar como se dará a formação dos "profissionais da educação", dentre eles o de Supervisão Escolar para atuação na Educação Básica, que se dará através dos cursos de Pedagogia ou em nível de pós-graduação.

A partir das Diretrizes Curriculares Nacionais para o Curso de Graduação em Pedagogia licenciatura, de 2006, não mais haverá separação em "Habilitações (Administração, Supervisão, Orientação Educacional,...), conforme previa as legislações educacionais anteriores, mas sim, será uma formação única, tanto para a docência, como para a função de "Especialistas em Educação, conforme citado nos artigos $9^{\circ}$ e $10^{\circ}$ da Resolução CNE/CP n ${ }^{\circ} 1$, de 15 de maio de 2006, que diz:

Art. $9^{\circ}$ Os cursos a serem criados em instituições de educação superior, com ou sem autonomia universitária e que visem à Licenciatura para a docência na Educação Infantil e nos anos iniciais do Ensino Fundamental, nos cursos de Ensino Médio, na modalidade Normal, de Educação Profissional na área de serviços e apoio escolar e em outras áreas nas quais sejam previstos conhecimentos pedagógicos, deverão ser estruturados com base nesta Resolução. Art. 10. As habilitações em cursos de Pedagogia atualmente existentes entrarão em regime de extinção, a partir do período letivo seguinte à publicação desta Resolução. (Brasil, 2006, p.5).

Conforme o artigo acima citado, percebe-se que para o exercício da função de coordenador pedagógico, faz-se necessário a formação em Pedagogia ou especialização na área. Esse novo cenário, porém, não mudou muito na prática, pois ainda os coordenadores pedagógicos carecem de uma formação mais específica, ou seja, mais aprofundada na sua área de atuação, principalmente no que diz respeito às suas atribuições, visto que com a extinção das habilitações específicas, a formação do pedagogo, especialista em educação, faz parte do curso de Pedagogia como um todo, reforçando o artigo 10 já mencionado anteriormente. 
Segundo Zieger (2011) são atribuições do pedagogo, que desempenha a função de coordenador pedagógico: responsável pelo planejamento, acompanhamento e avaliação do processo pedagógico, construção e implementação do projeto político-pedagógico, promover a formação continuada dos professores, acompanhar o processo de aprendizagem dos alunos, como também no diálogo com as famílias, juntamente com os professores. Todo esse trabalho requer do supervisor/coordenador pedagógico uma formação permanente que venha ao encontro das demandas educacionais da qual a escola está inserida.

O significativo papel do coordenador pedagógico, no processo de gestão é, segundo Libâneo (2018), de monitoramento constante da prática pedagógica dos professores, assim como processos de reflexão e investigação, tendo em vista que nem sempre esse profissional desempenha e cumpre genuinamente sua função dentro da escola, isto porque, como já foi afirmado anteriormente, ele faz parte de uma equipe gestora, e em determinadas situações terá que exercer outros papéis como diretor, orientador educacional e até mesmo professor de sala de aula, conforme afirma Oliveira \& Fernandes (2016).

Apesar de todas as atribuições desempenhadas pelo coordenador pedagógico no processo de gestão da escola, é de fundamental importância que se conheça o seu real papel. Contudo, não se pode discutir o papel do coordenador sem discutir a gestão democrática no contexto educacional, pois foi a partir dos pressupostos da gestão democrática que se repensa a estrutura de poder na escola.

Portanto, o coordenador pedagógico tem como uma das principais atribuições fazer a conexão entre todos os integrantes da comunidade escolar a fim de mobilizar para qualificar o processo de ensino e aprendizagem. Para tanto, se faz necessário discutir a formação continuada de professores, o projeto pedagógico escolar, a integração da comunidade escolar, onde o coordenador pedagógico é um dos principais articuladores nesse processo.

\subsection{O coordenador pedagógico e a formação continuada de professores}

Uma das principais atividades do coordenador pedagógico, no contexto da gestão escolar é organizar e fomentar o trabalho em equipe para a elaboração e desenvolvimento dos planejamentos e propostas pedagógicas. A ação do coordenador implica em estabelecer prioridades e tomada de decisões. Desse modo, cabe ao coordenador, juntamente com os demais membros da equipe gestora construir um projeto de formação continuada que torne a escola aprendente. Para isso, faz-se necessário que a reflexão coletiva seja um exercício sistemático, em que os professores sejam instigados a construir conhecimentos a partir da reflexão compartilhada, articulando conhecimentos práticos e as orientações teóricas.

Nessa perspectiva, Alarcão (2007) destaca a escola reflexiva como uma organização "aprendente que qualifica não somente os que nela estudam, mas os que nela ensinam ou apoiam estes e aqueles". Isso posto, faz-se necessário pensar sobre essa escola reflexiva, como ela se organiza, quem dela faz parte, o que ela ensina, o que dela se aprende. Isso implica em uma visão ampla de escola, ou seja, pensá-la na sua coletividade, nos muitos diálogos que nela são tecidos, nas contextualizações que ali são feitas.

A escola precisa constantemente ressignificar-se, e para isso, implica em mobilizar seus membros a refletirem sobre seu papel, de forma coletiva, assim sendo, uma escola reflexiva pauta-se no entendimento de um espaço de profundos diálogos, de espaços de mudança, que transforme seus membros em sujeitos capazes de, a partir das reflexões e problematizações que ali se constituem, transformar a escola num espaço humanizador e formativo.

Nessa seara é imprescindível pensar a formação continuada de professores como um dos principais desafios do trabalho do coordenador pedagógico. A formação continuada é entendida como um processo ao longo da profissão que, segundo Nóvoa, (1991) destaca: 
(...) deve estimular uma perspectiva crítico-reflexiva, que forneça aos professores os meios de um pensamento autônomo e que facilite as dinâmicas de autoformação participada. Estar em formação implica um investimento pessoal, um trabalho livre e criativo sobre os percursos e os projectos próprios, com vistas à construção de uma identidade, que é também uma identidade profissional. (Nóvoa, 1991, p. 25).

Isto não quer dizer que a formação continuada deva acontecer somente pela busca autônoma e solitária do professor, mas principalmente que esse professor tenha, na própria escola, variadas oportunidades de vivências dialógicas reflexivas, em que seja instigado e motivado à pesquisa e ressignificar sua própria prática pedagógica, que tenha espaços interativos para análise crítica da rotina e das demandas inerentes a sua atuação . Nesse sentido, cabe realçar que o coordenador pedagógico é o principal articulador desse processo de formação, o qual pode contribuir para transformar a escola para que se torne uma instituição aprendente e inovadora.

Uma vez que a inovação e mudança não se desenvolvem por imposições externas, são os gestores, os professores da escola, a partir das demandas da instituição que vão criar mecanismos impulsionadores das mudanças e transformações. Para tanto, Imbernón, (2011), ressalta que "a formação terá como base uma reflexão dos sujeitos sobre sua prática docente, de modo a permitir que examinem suas teorias implícitas, seus esquemas de funcionamento, suas atitudes etc., realizando um processo constante de autoavaliação que oriente seu trabalho."

Outro aspecto que merece destaque, no que se refere à formação continuada é a respeito dos saberes que os professores trazem consigo, que foram adquiridos ao longo da vida e aqueles adquiridos nas universidades. Esses saberes não devem ser rejeitados, pois referem-se, sobretudo, às vivencias pessoais dos educadores, e que estão intrinsecamente ligados a sua constituição como pessoa e como profissional. Nesse sentido, Tardiff (2014) destaca que:

Na realidade, no âmbito dos ofícios e profissões, não creio que se possa falar do saber sem relacioná-lo com os condicionantes e com o contexto do trabalho: o saber é sempre o saber de alguém que trabalha alguma coisa no intuito de realizar um objetivo qualquer. Além disso, o saber não é uma coisa que flutua no espaço: o saber dos professores o saber deles e está relacionado com a pessoa e a identidade deles, com a sua experiência de vida e com a sua história profissional, com as suas relações com os alunos em sala de aula e com os outros atores escolares na escola etc. (Tardiff, 2014, p.11).

Os saberes trazidos pelos docentes, a partir das diferentes realidades por eles vivenciadas, devem ser ressignificados, aprimorados à luz de novas propostas teóricas, ou seja, de fundamentações teóricas sólidas que provoquem uma profunda reflexão ao professor e, a partir de suas vivências, ele possa confrontar, balizado pelos estudos e reflexões que são mobilizados na escola, ressignificar seus saberes e sua prática pedagógica, contribuindo para o processo de ensino-aprendizagem dos alunos.

\subsection{O coordenador pedagógico e o processo de aprendizagem}

A aprendizagem constitui-se de um processo interno de mudança de comportamento que se dá através de fatores emocionais, neurológicos relacionais e ambientais. Para aprender faz-se necessário a união entre as estruturas mentais e o ambiente. Assim, são vários fatores que contribuem e interferem no processo de aprendizagem de um sujeito. Um dos fatores cruciais para que esse processo aconteça é a relação do sujeito com o meio com a qual ele convive, pois é na troca (mediação), ou seja, através da sua cultura, conforme afirma Rego (2014): "portanto, o desenvolvimento do ser humano depende do aprendizado que realiza num determinado grupo cultural, a partir da interação com outros indivíduos de sua espécie”. A partir dessa citação, evidencia-se que o ambiente ou grupo cultural da qual o sujeito faz parte, influencia diretamente no seu processo de aprendizagem. Esse processo de mediação entre sujeito e meio, ou entre sujeito e objeto, vai permitir a mudança de realidades, de contextos, a partir do momento em que esses "conhecimentos" que o sujeito já possui, os que adquire em contato 
com a sua cultura e com os objetos das quais interage, possibilita uma ressiginificação dos conhecimentos e a modificação desses contextos.

Voltando-se para a questão escolar, o processo de aprendizagem, nesse espaço, sobretudo, dar-se-á exatamente mediante as mediações entre os diferentes conhecimentos e experiências trazidos pelos alunos das diferentes realidades das quais eles convivem, que, com a mediação do professor e com o balizamento dos objetos do conhecimento que são apresentados na escola, os alunos fazem esse processo de construção e reconstrução das aprendizagens, e constroem o seu conhecimento.

Para que isso aconteça é fundamental que o professor conheça os seus alunos, suas realidades e a realidade onde a escola está inserida, para que seu planejamento seja voltado para a construção do conhecimento desses sujeitos, levando em consideração a "bagagem" social, cultural e histórica que os constitui, assim como as aprendizagens que vivenciaram advindas dessas realidades, conforme destaca (Wouters, et al., 2019): "O conhecimento, até então transmitido pelo professor, precisa ser produzido em sala de aula, com incentivo ao trabalho em equipe e à pesquisa, fazendo com que o aluno, e também o professor, aprenda a aprender para continuar aprendendo ao longo da vida", pois a aprendizagem se constrói no coletivo, nas interações e nas problematizações que são trabalhadas na sala de aula.

É diante dessas demandas que o coordenador pedagógico tem um papel fundamental, pois ele é o responsável por garantir o processo de aprendizagem dos alunos na instituição escolar. Libâneo (2018) aponta que dentre as atribuições específicas da coordenação pedagógica está a de "assegurar a unidade de ação pedagógica da escola, propondo orientações e ações de desenvolvimento do currículo e do ensino e gerindo as atividades curriculares e de ensino, tendo em vista a aprendizagem dos alunos". Dessa forma, é atribuição do coordenador pedagógico a tarefa de organizar o currículo da escola, no que tange ao planejamento dos professores, para que aconteça o processo de aprendizagem dos alunos.

Além do planejamento das ações educativas, o coordenador deve acompanhar o processo de avaliação das aprendizagens, ou seja, como se dá a avaliação desse processo, por parte dos professores, a partir de suas práticas e como o aluno está ou não avançando em suas aprendizagens.

Sabe-se que o processo avaliativo nas escolas tem sido alvo de muitas discussões e reflexões, tendo em vista a sua complexidade, frente às diferentes demandas que se apresentam no cenário educativo atual. Nesse sentido, o ato de avaliar decorre, sobretudo, dos processos metodológicos que o professor desenvolve na sua prática em sala de aula.

Durante muito tempo, na história da educação brasileira, tem-se construído um conceito bastante equivocado sobre avaliação da aprendizagem; conceito esse, baseado em pressupostos teóricos que visam, em última análise, à atribuição de notas e conceitos, através da aplicação de exames e provas, onde o resultado final seja a aprovação o a reprovação do aluno.

$\mathrm{Na}$ contramão desse processo, têm-se buscado refletir acerca da avaliação da aprendizagem, mobilizando os educadores e as instituições educativas a repensarem suas propostas avaliativas, visto que, no cenário educativo e social da qual se vive, que está em constante transformação, requer uma mudança de postura, de mentalidade e principalmente de prática educativa, e a avaliação é uma dessas situações que requer um novo olhar, sobretudo, no que diz respeito à forma como se avalia o processo de aprendizagem dos alunos, frente às demandas que se apresentam atualmente, buscando sobretudo, uma melhor qualidade na aprendizagem, e, por conseguinte, uma melhor qualidade no ensino.

Ao coordenador pedagógico, portanto, cabe o acompanhamento sistemático de todo o processo avaliativo que é desenvolvido na escola e, orientar, mobilizar os professores quanto aos processos avaliativos que estão desenvolvendo em suas salas de aula, a fim de que esses processos estejam em consonância com a proposta da escola e, principalmente, venham a promover uma qualidade no processo de aprendizagem do aluno. 


\subsection{O coordenador pedagógico e o projeto político pedagógico}

O Projeto Político Pedagógico constitui-se de um documento extremamente importante para todas as instituições de ensino, pois ele revela todos os valores, metas objetivos, diretrizes e como a escola consegue evoluir no processo de ensinoaprendizagem.

É projeto, pois consta de uma organização, de objetivos, de metas a serem cumpridas; é político, pois reflete a realidade da qual a escola está inserida, conta com a participação de todos os membros da comunidade escolar; e é pedagógico, pois trata dos processos de aprendizagem, das práticas educativas, do qual a escola vai calcar para que garanta a aprendizagem dos alunos, conforme afirma Libâneo (2018):

Por que a expressão pedagógico-curricular? (destaque do autor) $\mathrm{O}$ termo pedagógico é representativo de uma concepção de educação que considera a Pedagogia como a reflexão sistemática sobre as práticas educativas. Dessa reflexão resulta a formulação de objetivos e meios formativos para dar uma direção ao processo educativo. A ação pedagógica, portanto, não se refere ao "como se faz", mas, principalmente, ao "por que se faz", orientando o trabalho educativo para as finalidades sociais e políticas almejadas pelo grupo de educadores. Uma visão crítica da Pedagogia assume que ter uma atitude pedagógica (destaque do autor) é dar uma direção de sentido, um rumo, às práticas educativas, onde quer que elas sejam realizadas. (Libâneo, 2018, p.128).

O Projeto Político Pedagógico da escola, no que diz respeito a sua elaboração, deve contar com a participação de todos os membros da comunidade escolar, da qual estão nela inseridos, ou seja, professores, alunos, funcionários, pais ou responsáveis e demais instâncias colegiadas, pois deve ser refletido, discutido e elaborado no coletivo, onde todos os envolvidos no processo possam opinar, sugerir e principalmente refletir sobre os direcionamentos, objetivos e metas que serão traçados para que a escola reflita sua verdadeira realidade e seja fiel ao seu objetivo primordial, que é a garantia da aprendizagem dos alunos. Para isso, a elaboração do PPP, sobremaneira, deve priorizar a instauração de relações democráticas no ambiente escolar e contribuir para que essa democracia aconteça de fato, através da viabilização das discussões e debates sobre "a escola que temos" e a "escola que queremos", que são pressupostos para o início das discussões sobre o PPP.

Como mobilizador e articulador do processo de elaboração do PPP, o coordenador pedagógico desempenha uma função primordial, pois é ele quem vai reunir os diferentes membros da comunidade escolar e propor as discussões e articulações a respeito da realidade da escola, promover debates, estudos sobre autores que discorrem sobre o assunto que está sendo debatido e, mediar as discussões para que os membros da comunidade escolar reflitam, opinem e construam em parceria os objetivos, metas e estratégias que a escola precisa seguir para desenvolver sua missão. Esse processo de reunir, mobilizar e discutir com a comunidade é de fundamental importância, pois só assim se construirá um Projeto Político Pedagógico que reflita a verdadeira identidade da escola.

A partir de todas as discussões, reflexões e estudos desenvolvidos com a comunidade escolar, cabe ao coordenador pedagógico sistematizar e organizar as discussões e transformá-las em documento, fundamentando com os autores que dão suporte às discussões realizadas ao longo dos encontros que foram mobilizados. Esse documento deve ser aprovado por todos os segmentos da escola, mediante registro em ata, que ficará arquivada na escola.

Além da sistematização das discussões, cabe ao coordenador pedagógico garantir a implementação do Projeto Político Pedagógico na escola, juntamente com os demais membros da equipe gestora, como também, a divulgação do projeto a toda a comunidade escolar. A elaboração e sistematização do PPP possibilita o professor construir sua proposta de trabalho, tendo como base esse documento, que deve ser o orientador e os demais documentos e diretrizes que balizam a educação como um todo.

Cabe também ao coordenador pedagógico atualizar o PPP da escola, à medida que o que ali foi discutido e sistematizado, não mais retratar a realidade da escola, pois de tempos em tempos, a realidade escolar sofre mudanças, assim 
como a legislação educacional, surgem novas demandas e isso precisa ser revisto e atualizado, o que deve gerar novas discussões com todos os segmentos da escola, para que o PPP seja revisto e atualizado de acordo com a realidade da qual se está vivenciando na escola, como também no sistema educacional da qual a escola faz parte, garantindo, assim, a aprendizagem dos alunos.

\section{Resultados}

A partir das discussões tecidas acerca da problemática proposta, evidencia-se que o papel do coordenador pedagógico e suas atribuições no contexto escolar são cruciais para que as atividades pedagógicas se efetivem de forma plena. No decorrer da história, quando faz-se menção a respeito do coordenador pedagógico, percebe-se que esse termo ainda não era utilizado para designar o profissional que atuava como especialista em educação, tendo em vista as diferentes realidades históricas, sociais em que se vivenciou no Brasil, ao longo dos anos. Somente a partir da década de 1980, mais especificamente, no ano de 1988, com a promulgação da Constituição Federal, que enfatiza a descentralização do poder, a tomada de decisões de forma coletiva, através da gestão democrática. Com a promulgação da Lei de Diretrizes e Bases da Educação 9394/96, é que surge a figura do coordenador pedagógico, como articulador, mobilizador de todos atos educativos e pedagógicos da escola. Essa discussão acerca do coordenador pedagógico vem se aprofundando nos dias atuais, tendo em vista o seu papel no contexto educativo escolar. A gestão democrática, busca a descentralização do poder, a tomada de decisões, a partir do coletivo de uma instituição escolar, não somente centrada no diretor, mas em todos os membros colegiados que fazem parte do segmento educativo da escola. Nesse cenário, o coordenador pedagógico tem um papel fundamental, que, como membro de uma equipe gestora, garante a viabilização da gestão democrática e de seus princípios, a tomada de decisões e a descentralização do poder, contribuindo para a manutenção do processo de aprendizagem de todos os membros da comunidade educativa. $\mathrm{O}$ artigo 64 da Lei de Diretrizes e Bases 9394/96 aborda as questões legais que embasam o trabalho do coordenador pedagógico, sobretudo como se dá a formação para a atuação desse profissional na educação básica. Com a promulgação das Diretrizes Nacionais para o Curso de Pedagogia, de 2006, estabeleceu a formação inicial do coordenador pedagógico, primeiramente, como docente e, também, como especialistas em educação.

O coordenador pedagógico desempenha um importante papel no espaço escolar garantindo, promovendo, viabilizando e articulando um espaço de formação continuada dos professores, que, juntamente com os demais integrantes da equipe gestora, torna a escola um espaço de reflexão, de discussão e problematização dos processos, garantindo a efetivação da aprendizagem de professores e de alunos.

O processo de aprendizagem advém de fatores relacionais, neurológicos e ambientais. Para aprender o sujeito precisa construir relações com seus pares e com o meio onde estes vivem. Isso posto, a escola é o lugar onde as relações e interações acontecem, e cabe ao coordenador pedagógico organizar o currículo da escola, auxiliar os professores no planejamento de suas aulas como forma de garantir uma aprendizagem efetiva na escola. Outro ponto que merece destaque é com relação à avaliação, que é um assunto bastante complexo e que tem sido alvo de muitas discussões. Ao coordenador pedagógico cabe a função de acompanhar o processo educativo da escola, desde o planejamento e da metodologia adotada pelos professores, que estes estejam em consonância com a proposta educativa da escola e que promovam uma qualidade no processo de ensino.

O projeto político pedagógico é um dos documentos mais importantes da escola. Ele deve retratar os valores, metas características e como a escola deve avançar na garantia da aprendizagem dos que dela fazem parte. O papel do coordenador pedagógico, nesse aspecto, é de fundamental importância, visto que o projeto político pedagógico deve ser construído na coletividade, envolvendo todos os segmentos da comunidade educacional, e é nesse ponto que o coordenador deve proporcionar a reflexão, a discussão, a problematização dos assuntos que são pertinentes à realidade educativa, sistematizando e organizando todo o processo e, ao final, transformar essas discussões e sistematizações em documento que será balizador 
para que, a partir dele, os professores construam suas propostas de ensino, assim como a escola tenha um documento que oriente todo o processo pedagógico da escola.

Por fim, os resultados evidenciaram o papel fundamental que o coordenador pedagógico exerce na escola. Ele é um profissional que precisa estar preparado para acompanhar todo o processo educativo da escola, dando suporte aos professores, às famílias e a todos os envolvidos, para que a aprendizagem seja o principal acontecimento no cotidiano escolar.

\section{Conclusão}

Esse artigo buscou discutir o papel do coordenador pedagógico e a repercussão na gestão escolar, fazendo uma abordagem histórica desde o surgimento do termo "supervisão", na Grécia, e como esse termo impactou nos processos educativos, ao longo da história educacional brasileira.

Os períodos históricos vivenciados pelo Brasil foram determinantes para que se configurasse um modelo educacional que respondesse às realidades políticas e sociais que se configuravam e regulavam os regimes de verdade prescritos pela sociedade.

Nesses diferentes cenários, foi se constituindo o papel e as atribuições do coordenador pedagógico, e a sua identidade como articulador e mobilizador de um processo educativo, de tal forma que ele é o responsável por garantir que os processos de tomada de decisões, a coletividade e a descentralização do poder, de forma que as ações pedagógicas, sobretudo as aprendizagens sejam efetivados no ambiente escolar.

\section{Referências}

Alarcão, I (org.) (2007). Escola reflexiva e nova racionalidade. Artmed Editora.

Brasil (1968). Conselho Nacional de Educação. Lei n. 5540 de 28 de novembro de 1968. Estabelece as Diretrizes e Bases da Educação Nacional. República Federativa do Brasil. https://www2.camara.leg.br/legin/fed/lei/1960-1969/lei-5540-28-novembro-1968-359201-publicacaooriginal-1-pl.html.

Brasil (2006). Ministério da Educação. Resolução CNE/CP nº 1, 15 de maio de 2006. Institui Diretrizes Curriculares Nacionais para o Curso de Graduação em Pedagogia, licenciatura. Brasília: Diário Oficial da União. http://portal.mec.gov.br/cne/arquivos/pdf/rcp01_06.pdf.

Brasil (2010). LDB. Lei n. 9394 de 20 de dezembro de 1996. Estabelece as Diretrizes e Bases da Educação Nacional. (2a ed.), Editora Lamparina.

Brasil. (1988). Constituição da República Federativa do Brasil, publicada em 5 de outubro de $1988 . \quad$ Brasília (DF). http://www.planalto.gov.br/ccivil_03/constituicao/constituicao.htm .

Brasil. (2019). Ministério da Educação. Resolução CNE/CP nº 2, de 20 dezembro de 2019. Define as Diretrizes Curriculares Nacionais para a Formação Inicial de Professores para a Educação Básica e institui a Base Nacional Comum para a Formação Inicial de Professores da Educação Básica (BNC-Formação). Diário Oficial da União. http://portal.mec.gov.br/index.php?option=com_docman\&view=download\&alias=135951-rcp002-19\&category_slug=dezembro2019-pdf\&Itemid=30192.

Ferreira, N. S. C. (2012). Supervisão Educacional: uma reflexão crítica. (16a ed.), Ed. Vozes.

Fontana, F. (2018). Técnicas de pesquisa. In: T. Mazucato (org.). Metodologia da pesquisa e do trabalho científico. FUNEPE.

Imbernón, F (2011). Formação docente e profissional: formar-se para a mudança e a incerteza. Cortez.

Libâneo, J. C. (2018) Organização e gestão da escola: teoria e prática. (6a ed.), Heccus Editora.

Lück, H. (2009). Dimensões da gestão escolar e suas competências. Editora Positivo,

Lück, H. (2017). A gestão participativa na escola. Vozes.

Nóvoa, A. (1991). Os professores e a sua formação. (2a ed.), Editora Lisboa: Dom Quixote,

Oliveira, E. M. C. \& Fernandes, F. J. (2016). A construção da identidade do coordenador Pedagógico frente aos desafios da contemporaneidade: um compromisso entre as esferas estadual e municipal. In: M. L. I. S Colares \& S. H. X. Rocha (orgs.). O Coordenador Pedagógico no cotidiano da gestão escolar. 97 - 101. Editora CRV.

Oliveira, I. C. \& Menezes, I. V. (2018). Revisão de literatura: o conceito de gestão escolar. Cadernos de Pesquisa. 48 (169), 876-900. https://doi.org/10.1590/198053145341. https://www.scielo.br/j/cp/a/h8K6zLFps4LjXwjkqnBGPyD/?format=pdf\&lang=pt .

Rego, T. C. (2014). Vygotsky: uma perspectiva histórico-cultural da educação. Vozes, 
Richardson, R. J. (2012). Pesquisa Social: métodos e técnicas. (3a ed.), Atlas.

Rodrigues, P. A., \& Santos, E. A. G. (2019). Contribuições da formação continuada para prática pedagógica de professores de uma escola de Santa Maria. Research, Society and Development. 9 (2), 01-20. https://doi.org/10.33448/rsd-v9i2.1881. https://rsdjournal.org/index.php/rsd/article/view/1881.

Tardif, M. (2014). Saberes docentes e formação profissional. (17a ed.), Vozes.

Wouters, J. A. D., Locateli J. H. P., Santos, E. A. G., \& Carlesso, J. P. P. (2019) A Caverna, de José Saramago: o impacto da globalização no mundo do trabalho e na educação. Research Society and Development. 8 (1),01-15. https://doi.org/10.33448/rsd-v8i1.596. https://rsdjournal.org/index.php/rsd/article/view/596.

Zieger, L. (2011). Os saberes e fazeres da Supervisão Educacional: perspectivas teórico-práticas. In: M. Rangel (org.). Supervisão e gestão na escola conceitos e práticas de mediação. (3a ed.), 87-96. Papirus. 